Article

\title{
Low-Frequency RFID Signal and Power Transfer Circuitry for Capacitive and Resistive Mixed Sensor Array
}

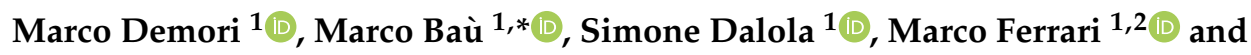 \\ Vittorio Ferrari ${ }^{1,2}$ (D) \\ 1 Department of Information Engineering, University of Brescia, Via Branze 38, 25123 Brescia, Italy; \\ marco.demori@unibs.it (M.D.); simone.dalola@unibs.it (S.D.); marco.ferrari@unibs.it (M.F.); \\ vittorio.ferrari@unibs.it (V.F.) \\ 2 INO-CNR (National Institute of Optics-National Research Council), Via Branze 45, 25123 Brescia, Italy \\ * Correspondence: marco.bau@unibs.it; Tel.: +39-030-3715896
}

Received: 14 May 2019; Accepted: 11 June 2019; Published: 14 June 2019

check for updates

\begin{abstract}
This paper presents a contactless measurement system for a mixed array of resistive and capacitive sensors exploiting a low-frequency radio-frequency identification (RFID)-based approach. The system is composed of a reader unit which provides power to and exchanges measurement data with a battery-less sensor unit. The sensor unit is based on a transponder operating at $134.2 \mathrm{kHz}$ and a microcontroller. The microcontroller sequentially measures the elements of the sensor array composed of $n$ capacitive and $m$ resistive sensors which share a common terminal. The adopted technique measures the charging time of a resistor-capacitor (RC) circuit, where the resistor or the capacitor can be either the sensing element or a reference component. With the proposed approach, the measured values of the resistive or capacitive elements of the sensor array are first-order independent from the supply voltage level. A prototype has been developed and experimentally tested with resistive elements in the range $400 \mathrm{k} \Omega-1.2 \mathrm{M} \Omega$ and capacitive elements in the range $200 \mathrm{pF}-1.2 \mathrm{nF}$ showing measurement resolution values of $1 \mathrm{k} \Omega$ and $5 \mathrm{pF}$, respectively. Operative distances up to $3 \mathrm{~cm}$ have been achieved, with readings taken faster than one element of the array per second.
\end{abstract}

Keywords: low-frequency RFID; capacitive and resistive sensors; contactless interrogation; power transfer

\section{Introduction}

The presence of sensors in everyday life and devices is becoming ubiquitous, among other reasons due to the emerging IoT (internet of things) scenario, where objects can become nodes of an intercommunicating network [1]. In this context, wired connections between nodes would be impractical, and hence wireless solutions are the preferred choice. At the same time, supplying power to the nodes is extremely challenging, also considering the scenario of disposable objects [2]. Especially in this latter case, batteries do not seem to be an option due to ecological and recycling issues and the maintenance required for battery replacement.

Energy harvesting solutions have received significant development and research efforts over the last decades, whereby mechanical configurations, energy conversion principles and electronic energy management circuits have been extensively investigated [3-5]. Specifically, energy can be harvested from vibrations, movement, thermal gradients and other sources. Harvesting energy from vibrations or movement can be achieved by means of converters generally based on piezoelectric, electrostatic or electrodynamic effects [6]. Several strategies have been adopted to increase the amount of energy harvested from broadband vibrations, overcoming the limitations of linear energy harvesters which 
best operate at their resonant frequency [7-13]. On the other hand, harvesting energy from thermal spatial gradients or time variations is typically based on thermoelectric [14] or pyroelectric effects [15], respectively. Energy harvesting is attractive but, though offering in principle an unlimited operation lifetime, demands an adequate amount of environment energy to be effectively harvested to supply the sensor unit.

Alternatively, contactless techniques can be adopted to interrogate passive sensors. One approach for passive mechanical resonators, which are required to be only electrically conductive, exploits externally induced eddy-currents [16]. Similarly, contactless interrogation can be achieved through an electromagnetic link between two coupled coils [17,18]. In [19-22], a primary coil is connected to the interrogation circuit, while a secondary coil is connected to a resonant sensor; i.e., a mechanical resonator such as a quartz crystal microbalance (QCM), a micro electro-mechanical system (MEMS) or an electrical resonant sensor such as an LC-tank circuit. The measurement principle can exploit both frequency-domain and time-domain techniques [21,22]. This approach relies on completely passive sensors; i.e., they do not require any active electronic circuits on board to operate.

A different approach exploits RFID technologies in the low frequency (LF), high frequency (HF) and ultra-high frequency (UHF) ranges [23]. In these cases, the reader energizes the sensor unit with an on-board transponder and they exchange data, exploiting the wireless link. The transponder can harvest energy through the RF link and operate as a bus bridge towards other devices, such as microcontrollers or digital sensors [24-28]. When a microcontroller is available, the number of sensors can be larger, provided that the energy budget is adequate to power them. Different microcontroller-based configurations have been proposed to interface resistive or capacitive sensors with low-power approaches [29-35]. Resistive and capacitive sensors are very attractive for disposable devices, because they can be adopted for the measurement of physical quantities, such as temperature and humidity, or chemical quantities, using them as gas sensors that can be applied to monitor, for example, food spoilage. In particular, low-cost gas sensors have been demonstrated in [36].

In this paper, a contactless system for a capacitive and resistive mixed sensor array is presented. By exploiting an RF link, the interrogation unit transfers energy and exchanges data with the sensor unit composed of a RFID transponder, a microcontroller and the sensor array. A measurement technique based on the charging time of suitable RC circuits advantageously allows to measure both the resistive and capacitive elements of the array. The RF link enables a complete contactless measuring technique. The prototyped system has been characterized and successfully applied to the measurement of both humidity and temperature of the air inside a package under different operating conditions.

\section{System Description}

Figure 1 shows the block diagram of the proposed RFID-powered contactless interface operating at the frequency of $134.2 \mathrm{kHz}$. The interface is composed of the reader unit (RU) and the sensor unit (SU) to which the resistive and capacitive mixed sensor array is connected. The RU consists of a RFID reader that manages both power transfer and data communication with the SU through the same RF link. The RU is based on a TMS3705 (Texas Instruments, Dallas, TX, USA) device that can be interfaced with a personal computer for commands and data management.

The SU includes an RF transponder and a microcontroller. The transponder is based on a TMS37157 (Texas Instruments, Dallas, TX, USA) device which collects the energy received through the RF link and operates as a serial peripheral interface (SPI) bridge towards the microcontroller. In particular, the transponder exploits the inductor $L_{\mathrm{T}}$, tuned with the capacitor $C_{\mathrm{T}}$ to set the operating frequency at $134.2 \mathrm{kHz}$, for both power transfer and data communication. The RF input of the transponder rectifies the voltage across the $L_{\mathrm{T}}-C_{\mathrm{T}}$ tank and stores the collected energy into the capacitor $C_{\mathrm{L}}$. The $3.3 \mathrm{~V}$ voltage regulator MCP1700-3V3 (Microchip Technology, Chandler, AZ, USA) regulates the voltage $V_{\mathrm{CL}}$, generating the voltage $V_{\mathrm{DD}}$ on the capacitor $C_{\mathrm{S}}$. The voltage $V_{\mathrm{DD}}$ then supplies both the digital interface of the transponder and the microcontroller. 


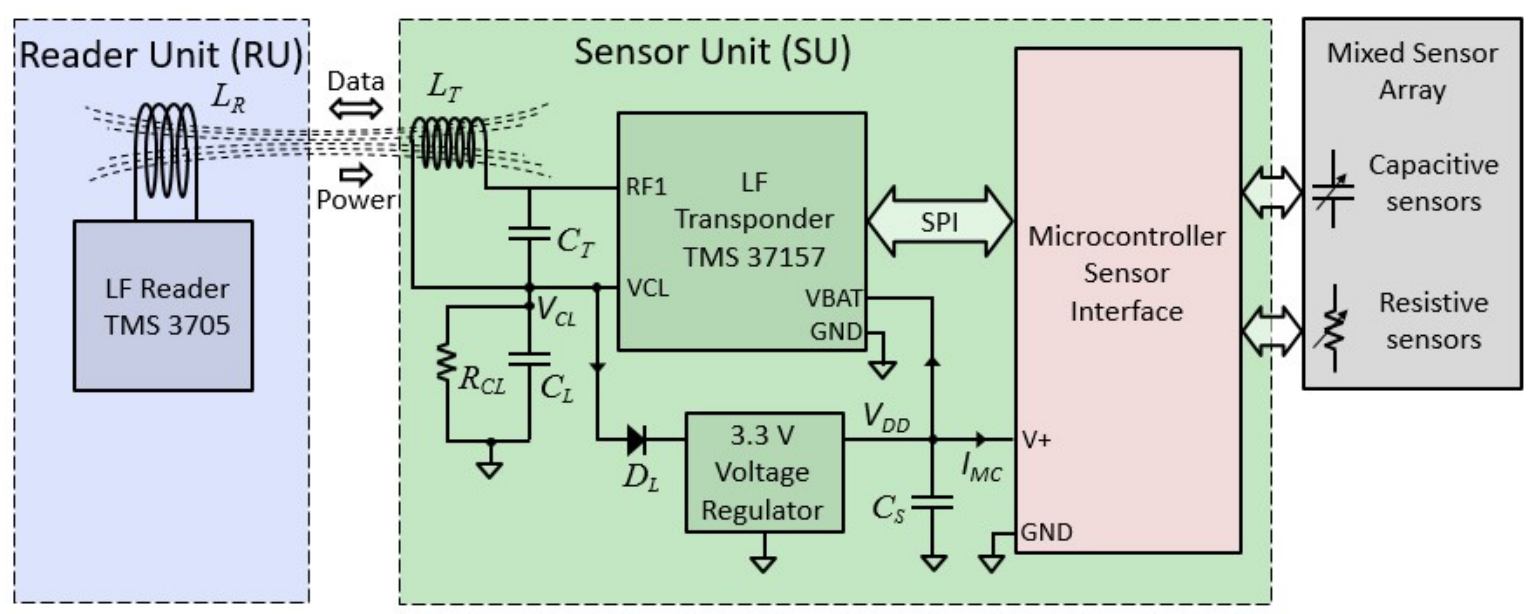

Figure 1. Block diagram of the radio-frequency identification (RFID) data and power transfer circuitry for capacitive and resistive mixed sensor array.

To implement the measurement procedure and transfer the measurement information to the transponder, an ultra-low-power microcontroller MSP430G2553 (Texas Instruments, Dallas, TX, USA) has been specifically selected since it embeds subsystems and functionalities required to interface the mixed sensor array, such as an analog comparator, counters, and low-power working modes [37]. The microcontroller interfaces the transponder through a SPI bus which allows the bidirectional communication of commands and measurement data. In particular, the commands sent to the microcontroller include the request to operate the measurement of a specific sensor element of the array.

Figure 2 shows the microcontroller sensor interface for the measurement of the elements of a mixed array of $n$ capacitive and $m$ resistive sensors. The resistive and capacitive sensors of the array have one common terminal, while the other terminal of each $C_{\mathrm{i}}$ capacitive and $R_{\mathrm{j}}$ resistive sensor is connected to a different $\mathrm{I} / \mathrm{O}$ pin of the microcontroller, named $\mathrm{P}_{\mathrm{Ci}}$ and $\mathrm{P}_{\mathrm{Rj}}$, respectively, with $i=1$ to $n$ and $j=1$ to $m$. The common terminal of the array is connected to ground through a reference capacitor $C_{\mathrm{M}}$ and to two I/O pins through a reference resistor $R_{\mathrm{REF}}$ and a discharge resistor $R_{\mathrm{DIS}}$. The voltage $V_{\mathrm{M}}$ across the capacitor $C_{\mathrm{M}}$ is fed to the non-inverting input of the comparator inside the microcontroller, while the inverting input is connected to an internal voltage reference at $V_{\mathrm{DD}} / 2$. The proposed configuration allows the measurement of the values of both $R_{\mathrm{j}}$ and $C_{\mathrm{i}}$ through the same technique based on the measurement of the charging time of either $C_{M}$ or $C_{M}+C_{i}$. 


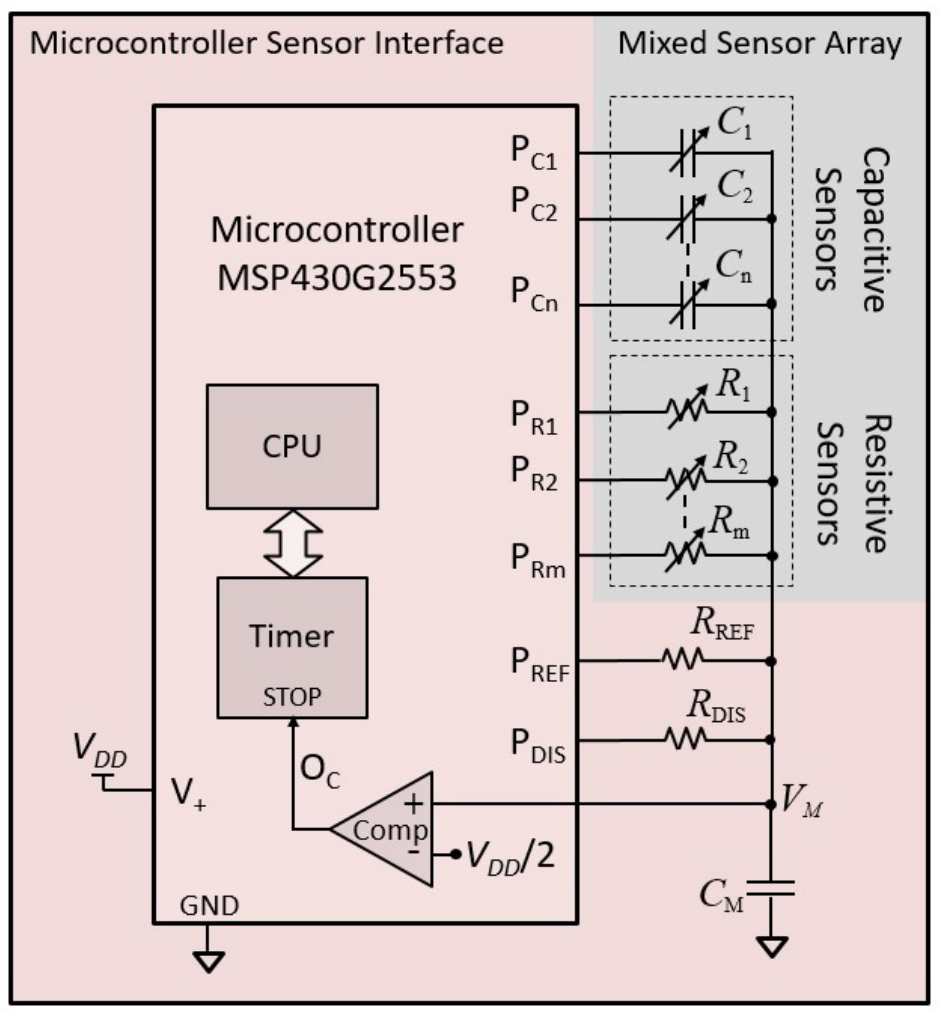

Figure 2. Microcontroller sensor interface for the capacitive and resistive mixed sensor array.

Figure 3a shows the relevant signals in the measurement cycle of the $x$-th resistive sensor $R_{\mathrm{x}}$. The measurement starts by configuring the pins $\mathrm{P}_{\mathrm{Ci}}$ (with $i=1, \ldots, n$ ), $\mathrm{P}_{\mathrm{Rj}}$ (with $j=1, \ldots, m$, with $j \neq x), \mathrm{P}_{\mathrm{REF}}$, and $\mathrm{P}_{\mathrm{DIS}}$ as inputs, i.e., setting them in the high-impedance state, while the pin $\mathrm{P}_{\mathrm{Rx}}$ is configured as output, i.e., in the low-impedance state. The logic level of $P_{R x}$ is set to high to charge the capacitor $C_{\mathrm{M}}$ through $R_{\mathrm{x}}$. Simultaneously, an internal timer is triggered to measure the time $T_{\mathrm{Rx}}$ elapsed between the charge starting time and the time when the voltage $V_{\mathrm{M}}$ reaches $V_{\mathrm{DD}} / 2$, causing the switching of the comparator output $\mathrm{O}_{\mathrm{C}}$ to the high logic level. This condition triggers the discharge of the capacitor $C_{\mathrm{M}}$ through the resistor $R_{\text {DIS }}$ whereby $\mathrm{P}_{\mathrm{DIS}}$ is configured as the output and set to low, while the pin $P_{R x}$ is configured as the input. The same charge-discharge sequence is then repeated by activating the pin $P_{\mathrm{REF}}$ and charging the capacitor $C_{\mathrm{M}}$ through $R_{\mathrm{REF}}$ to measure the reference charge time $T_{\mathrm{REF}}$. Accordingly, $R_{\mathrm{x}}$ can be determined as

$$
R_{x}=R_{R E F} \frac{T_{R x}}{T_{R E F}}=R_{R E F} \frac{N_{R x}}{N_{R E F}},
$$

where $N_{\mathrm{Rx}}=T_{\mathrm{Rx}} f_{\mathrm{CK}}$ and $N_{\mathrm{REF}}=T_{\mathrm{REF}} f_{\mathrm{CK}}$ are the timer counts corresponding to the charging times through $R_{\mathrm{x}}$ and $R_{\mathrm{REF}}$, respectively, and $f_{\mathrm{CK}}$ is the clock frequency of the timer. Equation (1) shows that the proposed measurement technique is independent of the values of the capacitance $C_{M}$ and the power supply voltage $V_{\mathrm{DD}}$. In the following, the value of $V_{\mathrm{DD}}$ will be assumed to be constant during the measurement cycle. 


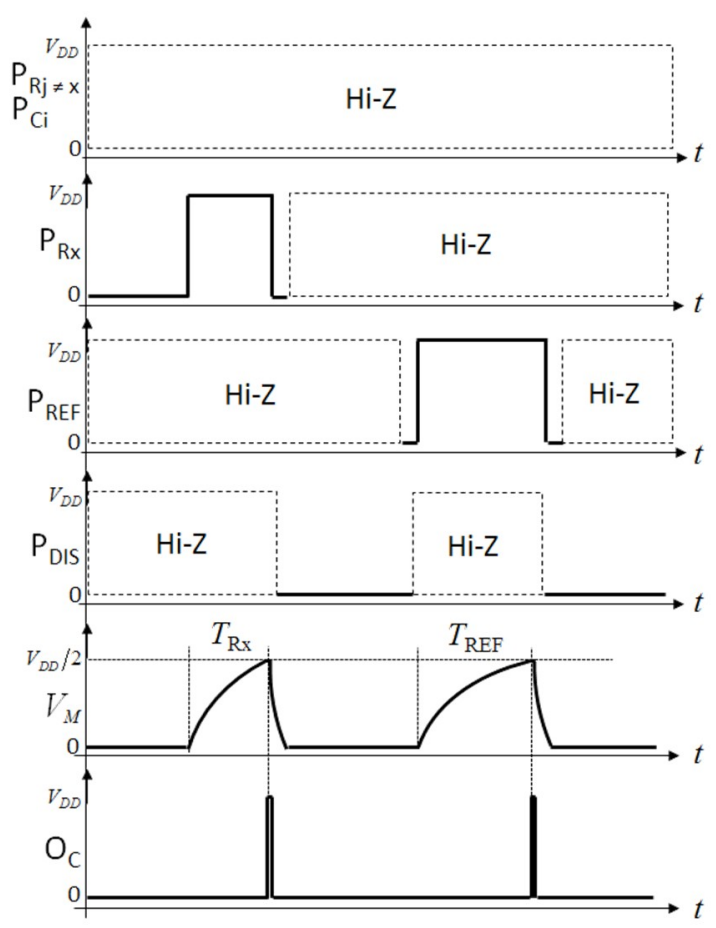

(a)

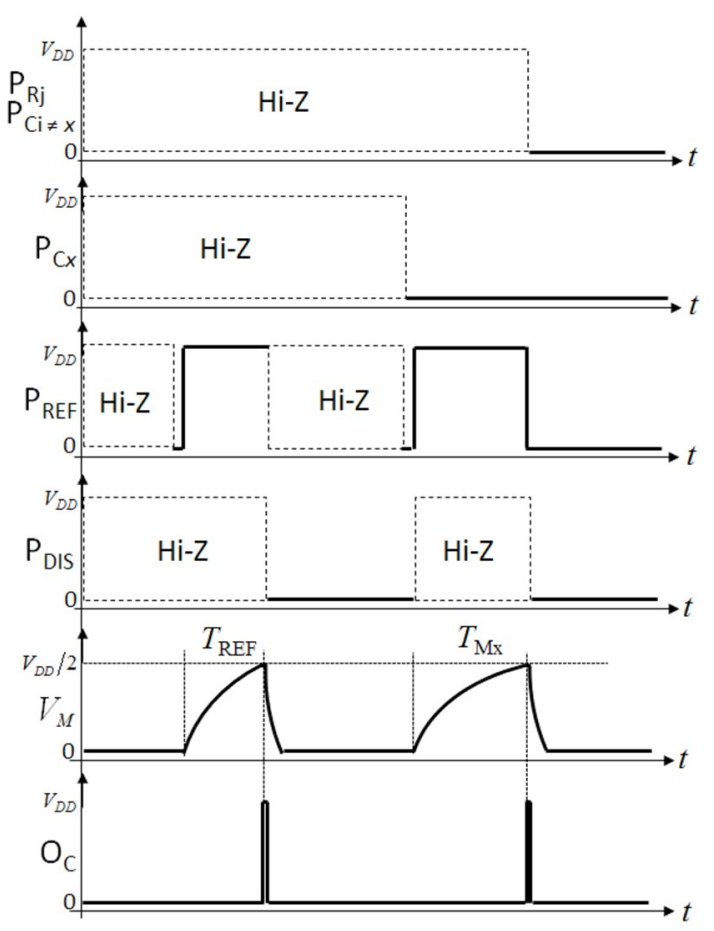

(b)

Figure 3. Operation of the microcontroller-based interface: (a) measurement cycle for the resistive sensor $R_{\mathrm{x}}$ (the charging times of $C_{\mathrm{M}}$ through $R_{\mathrm{x}}$ and $R_{\mathrm{REF}}$ are sequentially measured); (b) measurement cycle of the capacitive sensor $C_{\mathrm{x}}$ (the charging times of $C_{\mathrm{M}}$ and of $C_{\mathrm{x}}+C_{\mathrm{M}}$ through $R_{\mathrm{REF}}$ are sequentially measured).

Similarly, Figure 3b shows the relevant signals in the measurement cycle of the $x$-th capacitive sensor $C_{\mathrm{x}}$. The measurement technique of the capacitive sensors consists in the measurement of the charging time of the selected $x$-th capacitive sensor $\mathrm{C}_{\mathrm{x}}$ of the array through the known resistor $R_{\mathrm{REF}}$. The measurement starts by configuring all the pins $P_{C i}, P_{R j}$, and $P_{D I S}$ as inputs, while the pin $P_{R E F}$ is configured as output. The logic level of $\mathrm{P}_{\mathrm{REF}}$ is set to high to charge the capacitor $C_{\mathrm{M}}$ through $R_{\mathrm{REF}}$. Simultaneously, the internal timer is started to measure the time $T_{\mathrm{REF}}$ elapsed between the charge starting time and the time when the voltage $V_{\mathrm{M}}$ reaches $V_{\mathrm{DD}} / 2$. This condition triggers the discharge of $C_{\mathrm{M}}$ through the resistor $R_{\mathrm{DIS}}$ whereby the pin $\mathrm{P}_{\mathrm{REF}}$ is configured as input while $\mathrm{P}_{\mathrm{DIS}}$ is configured as output and set to low. Subsequently, the pin $\mathrm{P}_{\mathrm{Cx}}$ is configured as output and set to low, keeping the other pins $\mathrm{P}_{\mathrm{Rx}}, \mathrm{P}_{\mathrm{Cx}}$, and $\mathrm{P}_{\mathrm{DIS}}$ configured as inputs. This connects the capacitor $C_{\mathrm{x}}$ between the common terminal of the array and ground and thus in parallel with $C_{\mathrm{M}}$. The pin $P_{\mathrm{REF}}$ is set to high in order to measure the charging time $T_{\mathrm{Mx}}$ of the equivalent capacitance $C_{\mathrm{x}}+C_{\mathrm{M}}$ through $R_{\mathrm{REF}}$. Accordingly, the times $T_{\mathrm{REF}}$ and $T_{\mathrm{Mx}}$ can be expressed as

$$
\begin{gathered}
T_{R E F}=\ln (2) R_{R E F} C_{M}, \\
T_{M x}=\ln (2) R_{R E F}\left(C_{x}+C_{M}\right) .
\end{gathered}
$$

Then, the $C_{\mathrm{x}}$ can be determined as

$$
C_{x}=\frac{T_{M x}-T_{R E F}}{\ln (2) R_{R E F}}=\frac{1}{f_{C k}} \frac{N_{M x}-N_{R E F}}{\ln (2) R_{R E F}},
$$

where $N_{\mathrm{REF}}$ and $N_{\mathrm{Mx}}$ are the timer counts corresponding to the charging times of $C_{\mathrm{M}}$ and the equivalent capacitance $C_{\mathrm{x}}+C_{\mathrm{M}}$, respectively. Equation (4) shows that the proposed measurement technique is independent from the values of the capacitance $C_{\mathrm{M}}$ and the power supply voltage $V_{\mathrm{DD}}$. 
Different combinations of the values for $C_{\mathrm{M}}$ and $R_{\mathrm{REF}}$ can be adjusted with respect to those of the resistors and capacitors of the sensor array to set the measurement range avoiding the timer overflow. The measurement accuracy depends on the accuracy of the reference resistor $R_{\mathrm{REF}}$, and the capacitance measurement additionally depends on the accuracy of the clock frequency $f_{\mathrm{CK}}$.

To improve the measurement accuracy for capacitive sensors, the effect of the parasitic capacitance associated to the microcontroller pins has been considered. Figure $4 \mathrm{a}, \mathrm{b}$ shows the effect of the parasitic capacitances during the measurement of the charging times of $C_{M}$ and $C_{M}+C_{x}$, respectively. When the pins $\mathrm{P}_{\mathrm{Ci}}$ are configured as inputs, their parasitic capacitances $C_{\mathrm{Pi}}$ are connected in series with the corresponding $C_{\mathrm{i}}$, giving the contribution $C_{\mathrm{Ai}}=C_{\mathrm{i}} C_{\mathrm{Pi}} /\left(C_{\mathrm{i}}+C_{\mathrm{Pi}}\right)$. As a consequence, during the measurements of the charging times, the capacitances $C_{\mathrm{Ai}}$ add in parallel to $C_{\mathrm{M}}$ or $C_{\mathrm{M}}+C_{\mathrm{x}}$. Specifically, during the measurement of $C_{\mathrm{M}}$, all the pins are configured as inputs and $T_{\mathrm{REF}}$ becomes

$$
T_{R E F}=\ln (2) R_{R E F}\left(C_{M}+\sum_{i=1}^{n} \frac{C_{i} C_{P i}}{C_{i}+C_{P i}}\right) .
$$

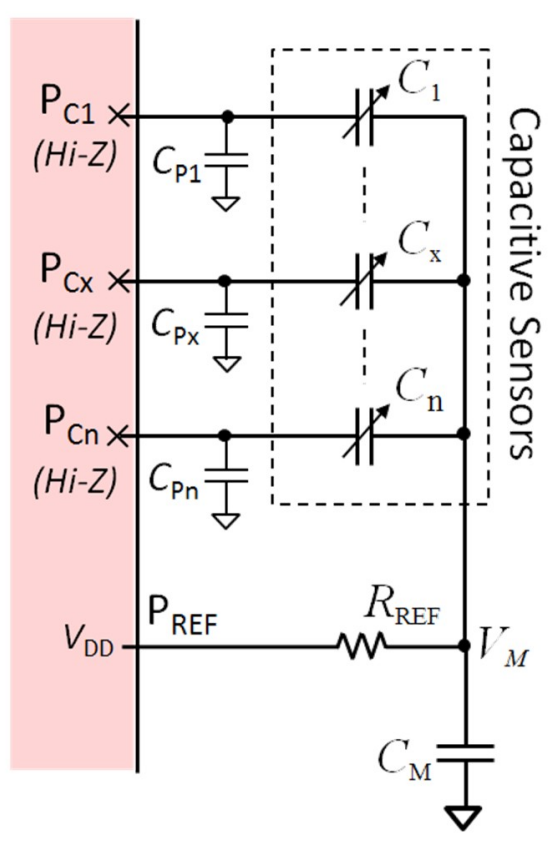

(a)

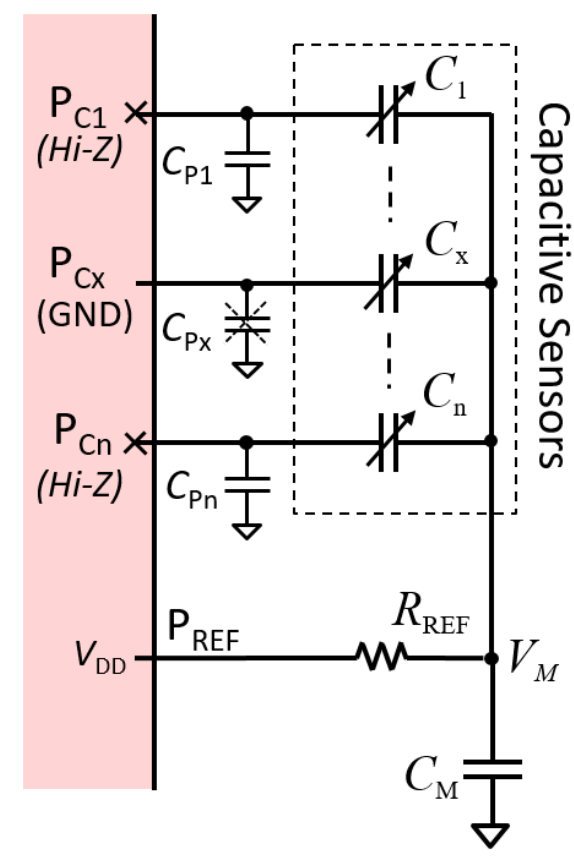

(b)

Figure 4. Effect of the parasitic capacitance $C_{\mathrm{Px}}$ of the microcontroller-based interface: (a) equivalent circuit during measurement with $C_{\mathrm{M}}$ and (b) during measurement with $C_{\mathrm{M}}+C_{\mathrm{x}}$.

During the measurement of $C_{\mathrm{M}}+C_{\mathrm{x}}$, the pin corresponding to $C_{\mathrm{x}}$ is set to low and the effect of the parasitic capacitance $C_{\mathrm{Px}}$ can be neglected. Hence, the time $T_{\mathrm{Mx}}$ becomes

$$
T_{M x}=\ln (2) R_{R E F}\left(C_{x}+C_{M}+\sum_{i=1}^{n} \frac{C_{i} C_{P i}}{C_{i}+C_{P i}}-\frac{C_{x} C_{P x}}{C_{x}+C_{P x}}\right) .
$$

Consequently, the resulting calculated capacitance $C_{x}^{*}$ is

$$
C_{x}^{*}=\frac{T_{M x}-T_{R E F}}{\ln (2) R_{R E F}}=C_{x}-\frac{C_{x} C_{P x}}{C_{x}+C_{P x}} .
$$

As a simplifying assumption, if all the $C_{\mathrm{Pi}}$ can be considered equal, their undesired effect can be compensated through a calibration procedure. The calibration requires the measurement of a known 
reference capacitor $C_{\mathrm{K}}$. Connecting $C_{\mathrm{K}}$ to the pins $\mathrm{P}_{\mathrm{Ci}}$, i.e., with $C_{\mathrm{x}}=C_{\mathrm{K}}$, the corresponding $C_{\mathrm{Px}}$ can be calculated from the measured value $C_{K}^{*}$ by inverting Equation (7) as

$$
C_{P x}=\frac{C_{K}}{C_{K}^{*}}\left(C_{K}-C_{K}^{*}\right) .
$$

Subsequently, from Equation (7), the known values of $C_{\mathrm{Px}}$ can be used to calculate the unaffected value of $C_{\mathrm{x}}$ from the measured $C_{x}^{*}$ as

$$
C_{x}=\frac{C_{x}^{*}+\sqrt{C_{x}^{* 2}+4 C_{x}^{*} C_{P x}}}{2}
$$

As far as the measurement of the resistive sensors is concerned, the effect of the parasitic capacitances can be neglected. In fact, the parasitic capacitances, in the order of few picofarads, combined with the resistors of the array, in the order of several hundreds of kiloohms, result in time constants which are much lower than those formed by the resistors of the array with the reference capacitance in the order of nanofarads.

\section{Experimental Results}

\subsection{Description of the System Prototype}

Figure 5 shows a picture of the developed system prototype comprising the SU and the RU. The proposed SU consist of a $20 \times 20 \mathrm{~mm}$ printed circuit board (PCB) which includes the transponder and the microcontroller-based interface. The transponder adopts a chip coil with inductance $L_{\mathrm{T}}=2.85 \mathrm{mH}$ tuned to the nominal operating frequency of $134.2 \mathrm{kHz}$ by means of a capacitor $C_{\mathrm{T}}=470 \mathrm{pF}$. Suitable external connections are provided to the capacitive and resistive mixed sensor array. A TMS37157 development tool (Texas Instruments, Dallas, TX, USA) was used as the RU which exploits a 43-mm diameter circular coil with $L_{\mathrm{R}}=442 \mu \mathrm{H}$ measured at $134.2 \mathrm{kHz}$.

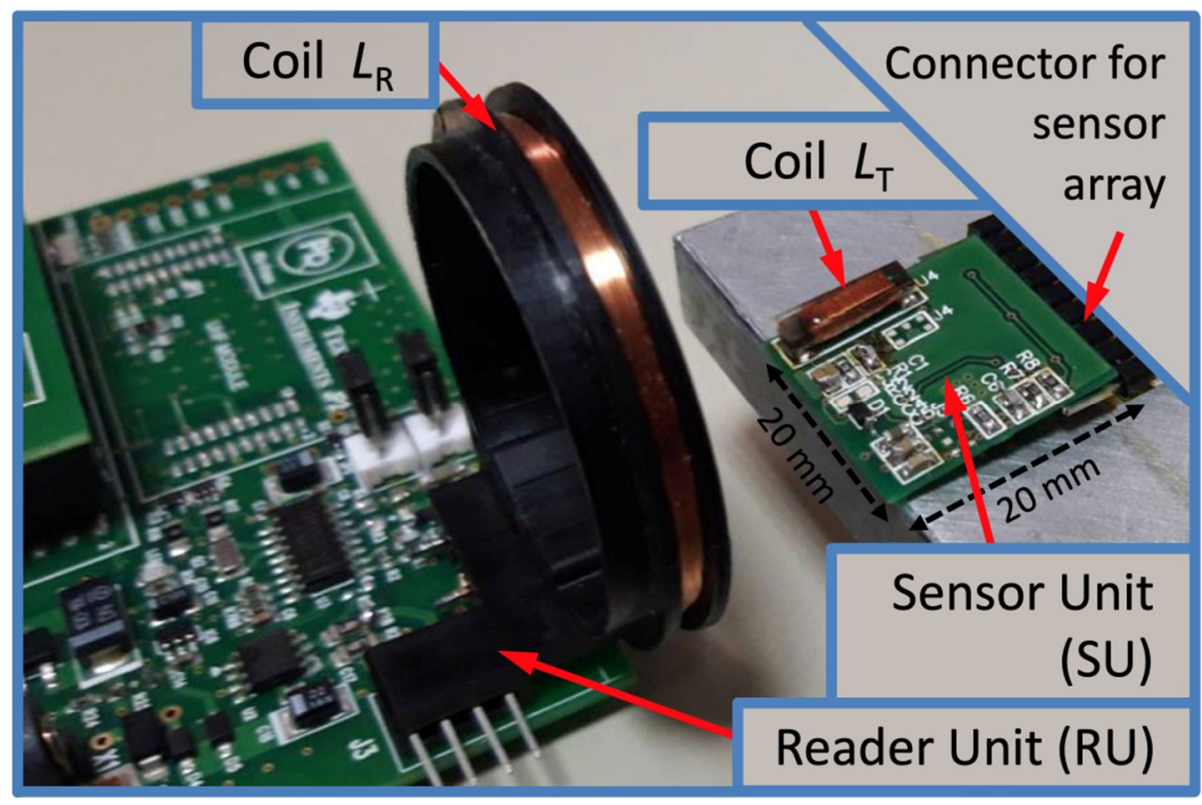

Figure 5. Picture of the developed system composed of the reader unit and the contactless interface.

The topology of the mixed sensor array is preconfigured in the RU which manages both the procedure for the measurement of each sensor and the complete measurement cycle of the mixed sensor array. In general, for a single measurement of $R_{\mathrm{x}}$ or $C_{\mathrm{x}}$ the RU sends to the SU the request to trigger a single measurement of the charging times $T_{\mathrm{Rx}}$ and $T_{\mathrm{REF}}$ for $R_{\mathrm{x}}$, or $T_{\mathrm{Mx}}$ and $T_{\mathrm{REF}}$ for $C_{\mathrm{x}}$. 
When the SU is powered by the RF field, the voltage regulator and the transponder turn on, while the microcontroller switches into sleep mode to save energy. Subsequently, the received command is transferred to the microcontroller through the SPI interface. The microcontroller wakes up, enters the active mode and in turn forces the transponder into sleep mode by sending the corresponding command through the SPI interface. The microcontroller performs the measurement of the requested charging time, reactivates the transponder and transfers the measurement data. As the final step, the reader turns off the RF field, and the transponder sends the data received from the microcontroller; i.e., the counts $N_{\mathrm{Rx}}, N_{\mathrm{Mx}}$ or $N_{\mathrm{REF}}$. The value of $R_{\mathrm{x}}$ is computed using Equation (1), while the value of $C_{\mathrm{x}}$ is computed using Equations (7) and (9) taking into account the parasitic capacitance $C_{\mathrm{Px}}$ estimated during the calibration phase.

For the complete measurement cycle of the mixed sensor array, the reader sends a request every $500 \mathrm{~ms}$ and waits for a reply from the transponder within a preset time window of $300 \mathrm{~ms}$. To avoid deadlock events, i.e., a missing reply, up to 5 consecutive attempts are performed before switching to the next sensor of the array.

A set of $n=3$ fixed capacitors and $m=3$ fixed resistors was connected to the microcontroller-based interface for the preliminary experimental characterization. With reference to the block diagrams of Figures 1 and 2, the voltages $V_{\mathrm{CL}}, V_{\mathrm{DD}}, V_{\mathrm{M}}$, the current $I_{\mathrm{MC}}$ and the RF field were simultaneously measured. The current $I_{\mathrm{MC}}$ was measured by a shunt resistor connected in series to the supply pin of the microcontroller. The RF field was sensed by an external probing coil placed closed to the reader coil. The distance between the RU and SU coils was set to $2 \mathrm{~cm}$.

Figure 6 shows the signals acquired at the beginning of the sequential measurements. It can be observed that, for the first two requests-i.e., the first two bursts of the RF field-not enough energy is stored into the capacitors $C_{\mathrm{L}}$ and $C_{\mathrm{S}}$ to allow the $\mathrm{SU}$ to power-up. In fact, the waveform of the current $I_{\mathrm{MC}}$ shows that the microcontroller does not enter the active mode. During the second burst, the voltage $V_{\mathrm{DD}}$ on the capacitor $C_{\mathrm{S}}$ reaches the regulated level of $3.3 \mathrm{~V}$, and the corresponding amount of energy is available for the following request. After the third burst, the measurement procedure is executed as it can be seen from the value of microcontroller current absorption and in the second short activation of the RF field by the RU, which confirms that data have been sent by the SU.

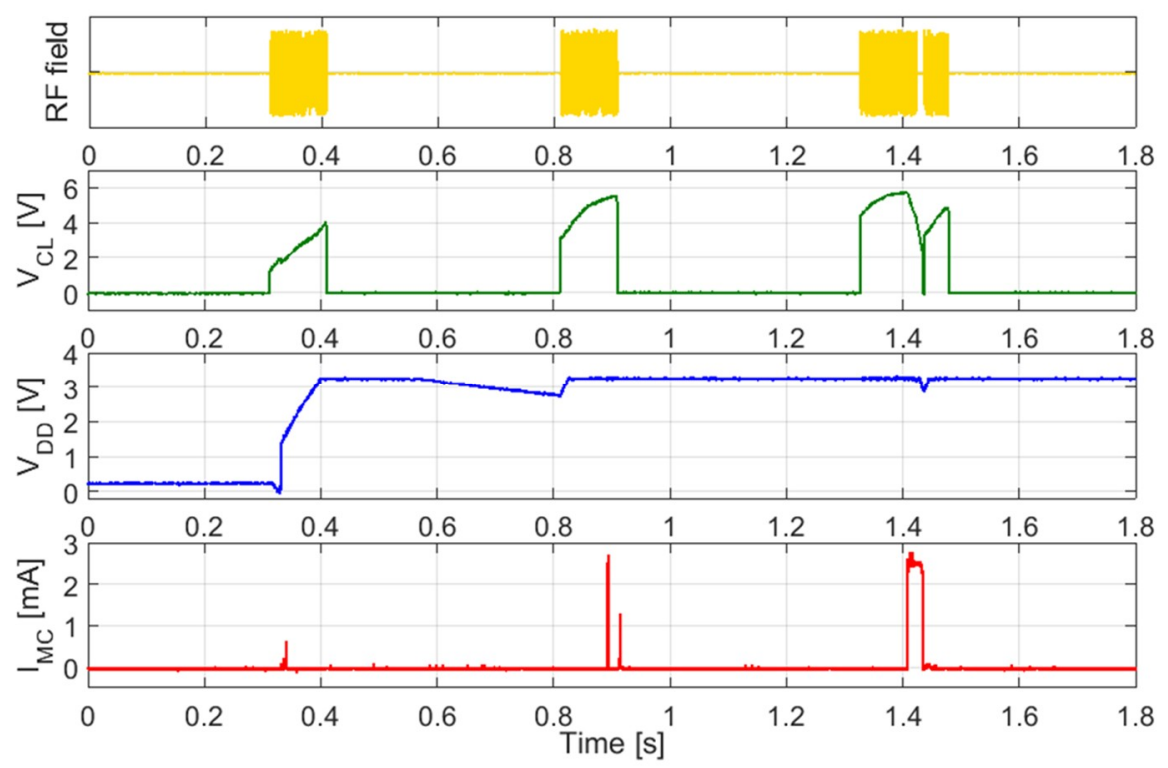

Figure 6. $V_{\mathrm{CL}}, V_{\mathrm{DD}}, I_{\mathrm{MC}}$ signals and RF field correspondent to the startup of sequential measurement cycles.

An enlarged view of the signals corresponding to a successful single measurement cycle is shown in Figure 7a. When the RF field is switched on, the voltage $V_{\mathrm{CL}}$ has an initial step of about $4 \mathrm{~V}$ 
followed by an incremental increase up to about $6 \mathrm{~V}$, while the voltage $V_{\mathrm{DD}}$ is kept fixed at $3.3 \mathrm{~V}$ by the voltage regulator. After $80 \mathrm{~ms}$, the command transmission is completed and the transponder activates the microcontroller, as confirmed by the current $I_{\mathrm{MC}}$ that increases up to about $2.5 \mathrm{~mA}$; i.e., the current absorption in active mode. The power consumption of the microcontroller causes the discharge of the capacitor $C_{\mathrm{L}}$ with a corresponding decrease of the voltage $V_{\mathrm{CL}}$. After $20 \mathrm{~ms}$ from the onset of the active mode, $V_{\mathrm{CL}}$ goes below $3.4 \mathrm{~V}$ and the voltage regulator turns off. However, as shown in Figure $7 \mathrm{~b}$, the energy stored into the capacitor $C_{S}$ allows the microcontroller to stay powered to complete the operation. The time duration for a single measurement cycle is about $27 \mathrm{~ms}$. Figure $7 \mathrm{~b}$ shows two subsequent charge-discharge cycles of $C_{\mathrm{M}}$ during which $V_{\mathrm{DD}}$ is kept constant, ensuring the effectiveness of the applied method, as discussed in Section 2.

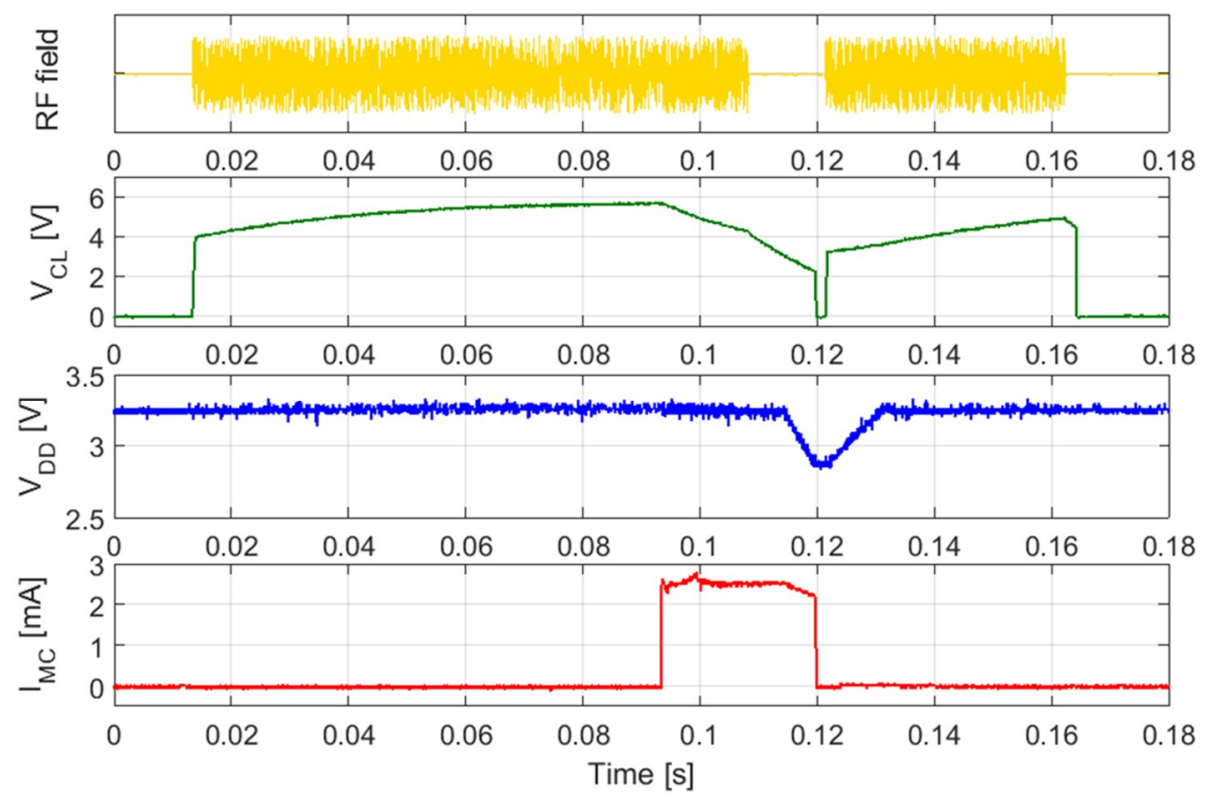

(a)
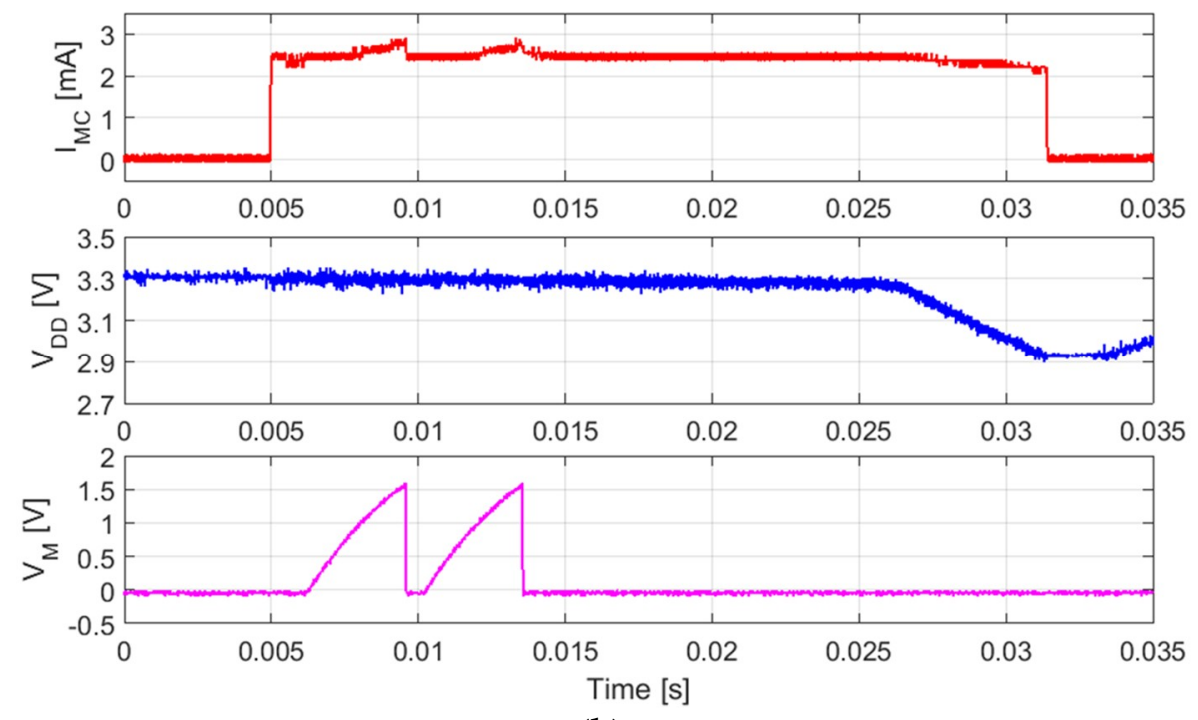

(b)

Figure 7. (a) RF field and $V_{\mathrm{CL}}, V_{\mathrm{DD}}, I_{\mathrm{MC}}$ signals during a single measurement cycle; (b) detailed view of $I_{\mathrm{MC}}, V_{\mathrm{DD}}$ and $V_{\mathrm{M}}$ during the measurement. 
To evaluate the measurement repeatability of the proposed system, two different arrays were tested for a total of six different resistors and six different capacitors. In the experimental tests, the values of $C_{\mathrm{M}}, R_{\mathrm{REF}}$ and $R_{\mathrm{DIS}}$ were set to $4.7 \mathrm{nF}, 1 \mathrm{M} \Omega$ and $1 \mathrm{k} \Omega$, respectively.

Each resistor, chosen in the range between $390 \mathrm{k} \Omega$ and $1.2 \mathrm{M} \Omega$, was consecutively measured $N=40$ times. and the corresponding average value $\overline{R_{j}}$ was compared with the reference value $R_{\mathrm{j}}$ measured by a multimeter Fluke 8840A (Fluke Corporation, Everett, WA, USA). Table 1 reports the reference values $R_{\mathrm{j}}$, the average values $\overline{R_{j}}$, and the corresponding standard deviations $\sigma_{R j}$, respectively. The repeatability for the resistive measurements, which sets the resolution, is estimated at $\sigma_{\mathrm{Rj}}$, resulting in between $0.5 \mathrm{k} \Omega$ to $1 \mathrm{k} \Omega$. The relative resolution $\sigma_{R \mathrm{j}} / R_{\mathrm{j}}$ is about $0.1 \%$.

Table 1. Reference values $R_{\mathrm{j}}$, average values $\overline{R_{j}}$, standard deviations $\sigma_{R \mathrm{j}}$ and relative resolution $\sigma_{R \mathrm{j}} / R_{\mathrm{j}}$ estimated over $N=40$ repeated measurements obtained with the system prototype.

\begin{tabular}{cccc}
\hline Reference Value $\boldsymbol{R}_{\mathbf{j}}$ & Average Measured Value $\overline{\boldsymbol{R}_{\boldsymbol{j}}}$ & Standard Deviation $\boldsymbol{\sigma}_{\boldsymbol{R} \mathbf{j}}$ & Relative Resolution $\boldsymbol{\sigma}_{\boldsymbol{R} \mathbf{j}} / \boldsymbol{R}_{\mathbf{j}}$ \\
\hline $390.98 \mathrm{k} \Omega$ & $392.2 \mathrm{k} \Omega$ & $0.5 \mathrm{k} \Omega$ & $0.13 \%$ \\
$467.08 \mathrm{k} \Omega$ & $468.8 \mathrm{k} \Omega$ & $0.4 \mathrm{k} \Omega$ & $0.09 \%$ \\
$678.14 \mathrm{k} \Omega$ & $681.5 \mathrm{k} \Omega$ & $0.6 \mathrm{k} \Omega$ & $0.13 \%$ \\
$828.03 \mathrm{k} \Omega$ & $832.7 \mathrm{k} \Omega$ & $0.9 \mathrm{k} \Omega$ & $0.11 \%$ \\
$1.0012 \mathrm{M} \Omega$ & $1.001 \mathrm{M} \Omega$ & $1 \mathrm{k} \Omega$ & $0.10 \%$ \\
$1.2012 \mathrm{M} \Omega$ & $1.201 \mathrm{M} \Omega$ & $1 \mathrm{k} \Omega$ & $0.08 \%$ \\
\hline
\end{tabular}

The relative errors $e_{\mathrm{Rj}}=\left(\overline{R_{j}}-R_{\mathrm{j}}\right) / R_{\mathrm{j}}$ have been calculated as an estimation of the resistance measurement accuracy. Figure 8 reports the relative errors as a function of the measured reference values $R_{\mathrm{j}}$, evidencing $e_{\mathrm{Rj}}$ less than $0.6 \%$ in the considered range.

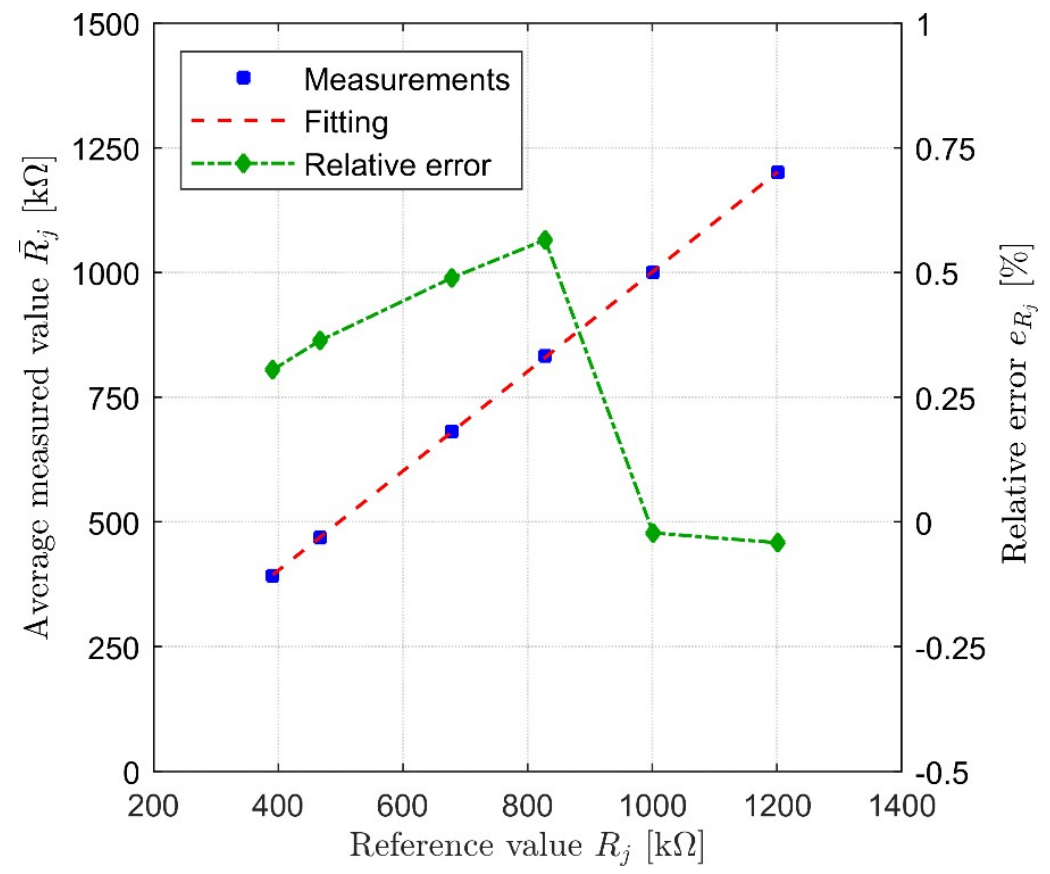

Figure 8. Average values $\overline{R_{j}}$ calculated over 40 repeated measurement and relative errors $e_{\mathrm{Rj}}$ versus the measured reference values $R_{\mathrm{j}}$ of the resistors.

Similarly, each capacitance, chosen in the range between $220 \mathrm{pF}$ and $1.2 \mathrm{nF}$, was consecutively measured $N=40$ times, and the corresponding average value $\overline{C_{i}}$ was compared with the reference value measured by a capacitance meter E4981A (Keysight Technologies, Santa Rosa, CA, USA) at the frequency of $120 \mathrm{~Hz}$. Table 2 reports the reference values $C_{\mathrm{i}}$, the average values $\overline{C_{i}}$ and the corresponding standard deviations $\sigma_{C i}$, respectively. The repeatability for the capacitive measurements, 
which sets the resolution, is estimated at $\sigma_{\mathrm{Ci}}$ resulting in between $1 \mathrm{pF}$ to $5 \mathrm{pF}$. The relative resolution $\sigma_{\mathrm{Ci}} / C_{\mathrm{i}}$ is in the range between $0.12 \%$ and $1.8 \%$.

Table 2. Reference values $C_{\mathrm{i}}$, average values $\overline{C_{i}}$, standard deviations $\sigma_{\mathrm{Ci}}$ and relative resolution $\sigma_{C \mathrm{i}} / C_{\mathrm{i}}$ estimated over $N=40$ repeated measurements obtained with the system prototype.

\begin{tabular}{cccc}
\hline Reference Value $\boldsymbol{C}_{\mathbf{i}}$ & Average Measured Value $\overline{\boldsymbol{C}_{\boldsymbol{i}}}$ & Standard Deviation $\boldsymbol{\sigma}_{\boldsymbol{C} \mathbf{i}}$ & Relative Resolution $\boldsymbol{\sigma}_{C_{\mathbf{i}}} / \boldsymbol{C}_{\mathbf{i}}$ \\
\hline $221.2 \mathrm{pF}$ & $224 \mathrm{pF}$ & $4 \mathrm{pF}$ & $1.8 \%$ \\
$318.1 \mathrm{pF}$ & $317 \mathrm{pF}$ & $4 \mathrm{pF}$ & $1.3 \%$ \\
$459.3 \mathrm{pF}$ & $458 \mathrm{pF}$ & $5 \mathrm{pF}$ & $1.1 \%$ \\
$552.1 \mathrm{pF}$ & $551 \mathrm{pF}$ & $1 \mathrm{pF}$ & $0.12 \%$ \\
$915.5 \mathrm{pF}$ & $914 \mathrm{pF}$ & $3 \mathrm{pF}$ & $0.33 \%$ \\
$1.179 \mathrm{nF}$ & $1.191 \mathrm{nF}$ & $2 \mathrm{pF}$ & $0.17 \%$ \\
\hline
\end{tabular}

The relative errors $e_{\mathrm{Ci}}=\left(\overline{C_{i}}-C_{\mathrm{i}}\right) / C_{\mathrm{i}}$ were calculated as an estimation of the capacitance measurement accuracy. Figure 9 reports the relative errors as a function of the measured reference values $C_{i}$, evidencing $e_{\mathrm{Ci}}$ lower than $1 \%$ in the considered range.

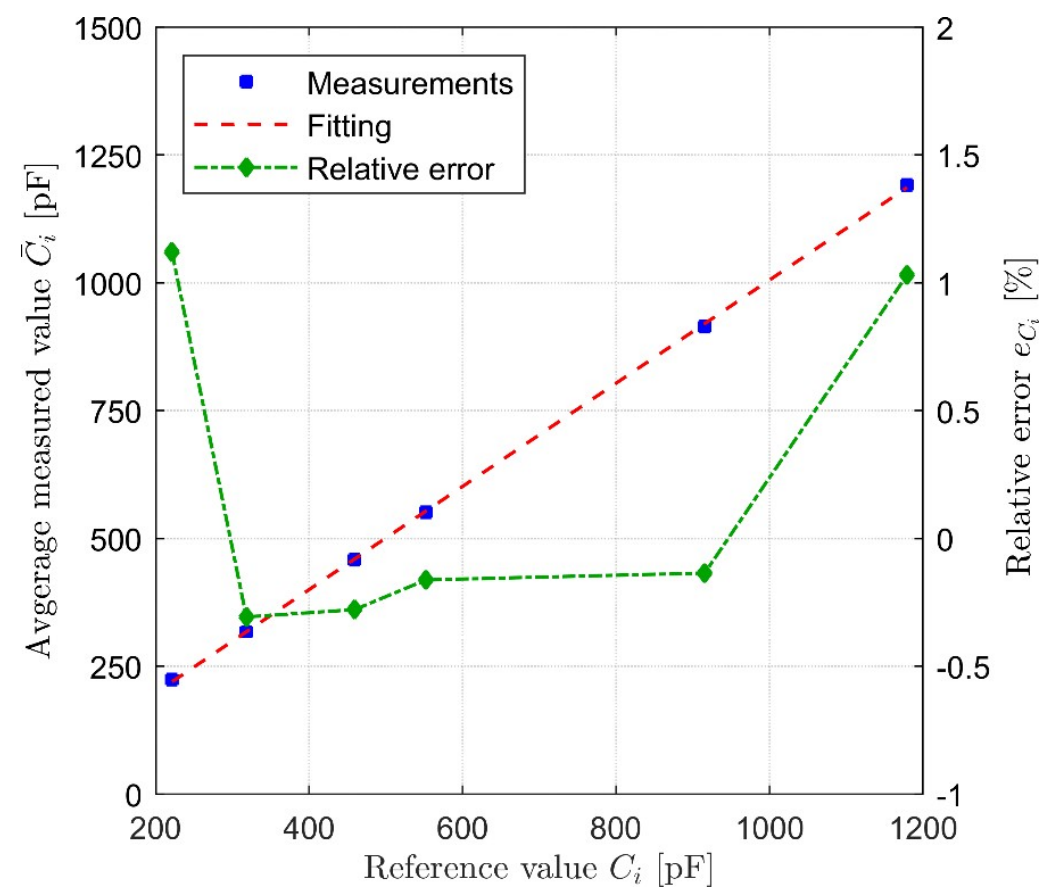

Figure 9. Average values $\overline{C_{i}}$ calculated over 40 repeated measurement and relative errors $e_{\mathrm{Ci}}$ versus the measured reference values $C_{i}$ of the capacitors.

\subsection{Array of Temperature and Humidity Sensors}

The proposed system was experimentally validated with a sensor array composed of two resistive temperature sensors and two humidity capacitive sensors. The temperature sensors are NTCG16QH334 (TDK, Chuo, Japan) NTC thermistors with a resistance given by $R_{\mathrm{T}}=R_{0} e^{B(1 / T-1 / T 0)}$, where $R_{0}=330 \mathrm{k} \Omega$ at $T_{0}=298 \mathrm{~K}, B=4662 \mathrm{~K}$ and $T$ is the temperature in Kelvin. The relative humidity (RH) sensors are H6000 (Gefran S.p.A., Provaglio d'Iseo, Italy) devices with a nominal capacitance of $500 \mathrm{pF}$ at 75\% RH and sensitivity of about $1 \mathrm{pF} / \% \mathrm{RH}$.

In the first test, the four sensors were measured during sequential exposures to a hot air jet and a high-humidity air jet, respectively, in order to evaluate the system response to temperature and humidity. Figure 10a,b shows the measured resistance values and the corresponding temperature trends versus time, and the measured capacitance values and the corresponding RH trends versus time, 
respectively. As can be observed, a reading is received from the SU every $0.5 \mathrm{~s}$, which corresponds to a measurement rate for each sensor of one reading every $2 \mathrm{~s}$.

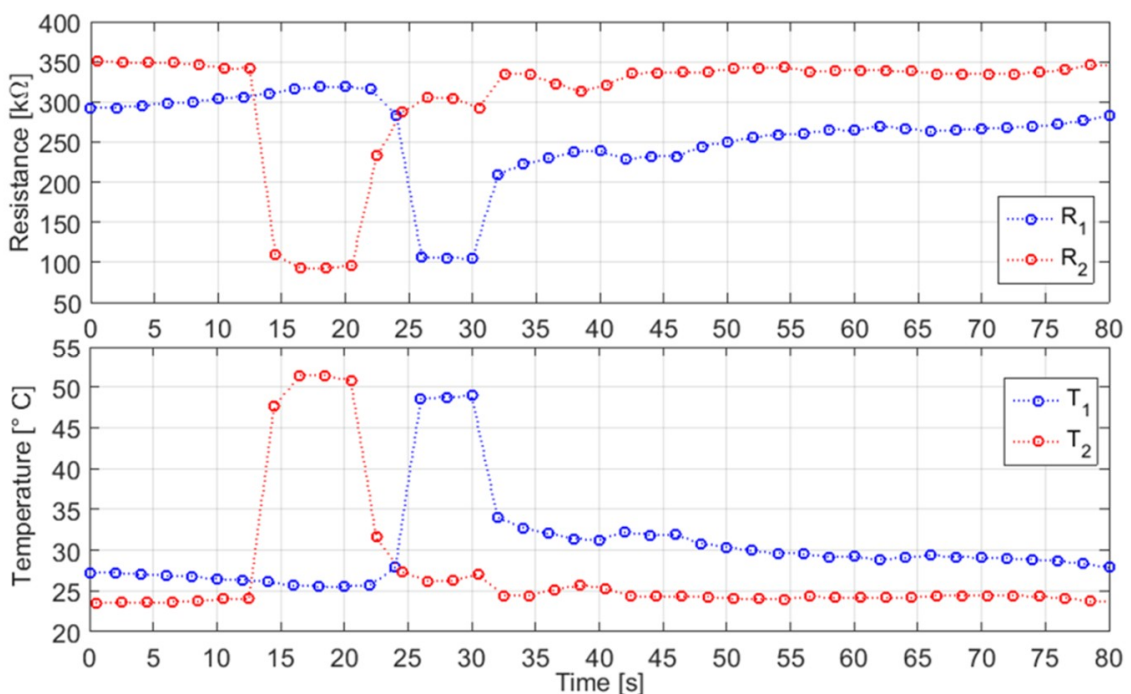

(a)

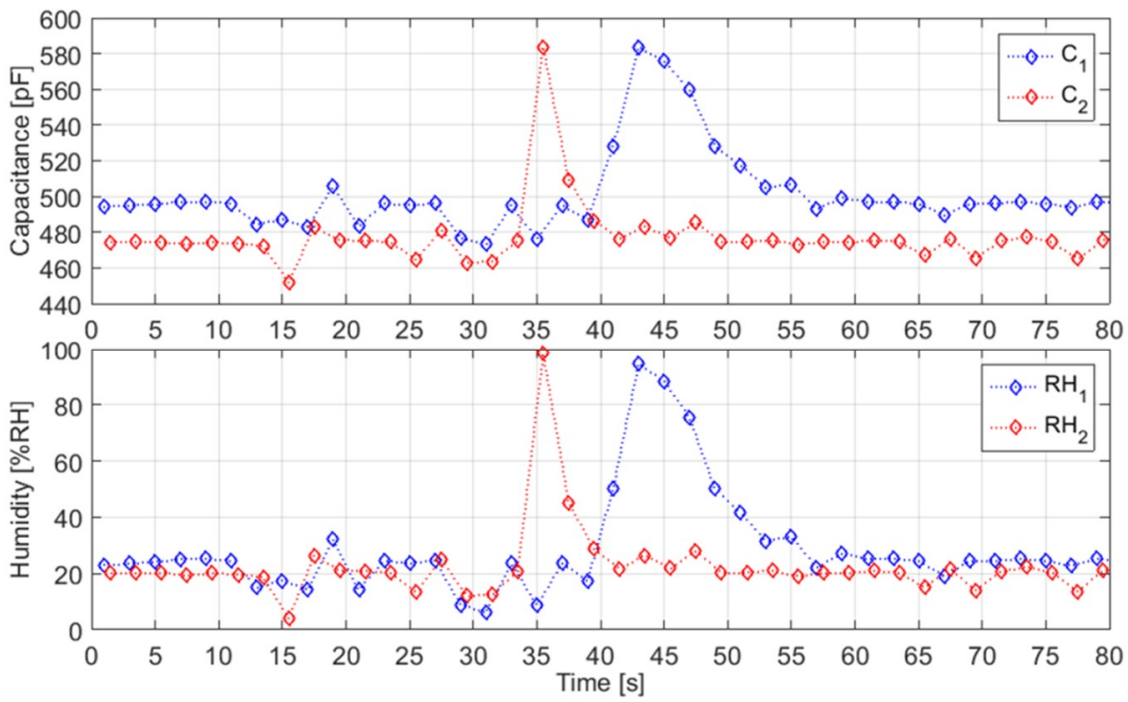

(b)

Figure 10. Continuous measurement of temperature and relative humidity (RH) with the system prototype: (a) measured resistance and temperature trends versus time; (b) measured capacitance and relative humidity trends versus time.

As a final test application, the contactless monitoring of the temperature and humidity inside a hermetic food box was investigated. A temperature and humidity sensor pair NTCG16QH334 (TDK, Chuo, Japan) and H6000 (Gefran S.p.A., Provaglio d'Iseo, Italy) were placed inside the box, while an additional pair of identical sensors were kept outside to monitor the ambient temperature and humidity. A humidified sponge was placed inside the box as a humidity source. The monitoring of the temperature and humidity was performed by activating the SU placed outside the box every $2 \mathrm{~min}$ and collecting $N=10$ consecutive measurements for each sensor. Figure 11 shows the temperature and humidity values measured by each of the four sensors during the test. 


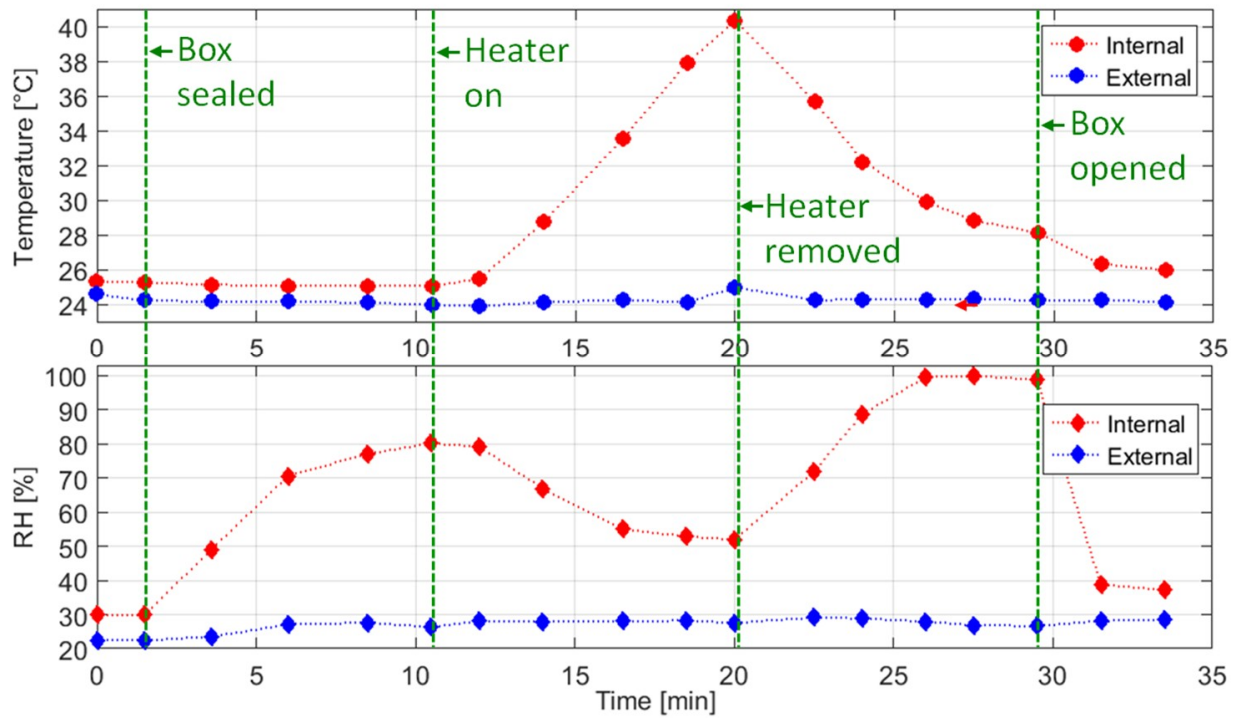

Figure 11. Temperature and humidity trends measured from the sensor unit (SU) placed into a food box during the test, composed of four different phases.

The test was divided into four phases. At the beginning, the box with the sponge inside is sealed. The humidity sensor inside the box detects an increase of $\mathrm{RH}$ up to about $80 \% \mathrm{RH}$, while the response of the external sensor remains almost constant, as it will be throughout all the duration of the test. Subsequently, the box is placed on a heater. An increase of temperature inside the box up to about $40^{\circ} \mathrm{C}$ is detected by the internal temperature sensor, with a corresponding measured internal humidity decrease down to $50 \% \mathrm{RH}$, as expected. In the next phase, the box is removed from the heater and a corresponding decrease of the internal temperature and increase of the humidity up to $100 \% \mathrm{RH}$ were detected. In the last phase, the box is opened, and a corresponding decrease of the measured internal humidity was consistently detected.

\section{Discussion and Conclusions}

A contactless system for the measurement of resistive and capacitive mixed sensor arrays has been presented. Contactless operation has been achieved by the exploitation of a low-frequency RFID link operating at $134.2 \mathrm{kHz}$. An external reader unit (RU) energizes the battery-less sensor unit (SU) and exchanges measurement data which can subsequently undergo post-processing elaboration. The $\mathrm{SU}$ is based on a RFID transponder and a microcontroller devoted to the measuring process and connected to a resistive and capacitive mixed sensor array. The $\mathrm{SU}$ was designed with the constraint of a minimum count of on-board electronic components in order to minimize power consumption. A key step in the development was the adoption of low-power ratiometric sensor measurement techniques based on the charging time of suitable RC circuits unaffected by the specific value of the supply voltage.

The prototyped SU is as small as $2 \times 2 \mathrm{~cm}$, ensuring the possibility of embedding it in disposable or portable sensorized objects to be monitored on-demand without any physical connection or on-board energy sources. The maximum working distance is about $3 \mathrm{~cm}$ and depends on the reader-transmitted power, the dimension/alignment and the presence of metallic objects near to the transmitting and receiving coils.

The proposed system was validated on reference resistors and capacitors, showing maximum relative deviations with respect to reference values of $0.6 \%$ and $1.2 \%$, respectively. In particular, the accuracy in the measurement of the capacitive elements was improved thanks to dedicated calibration procedures. Other systems reported in the literature based on the measurement of charging time can achieve deviations of the measured resistors with respect to reference values as low as $0.03 \%$ [31] and $0.05 \%[32,34]$ in the resistive range of up to about $150 \mathrm{k} \Omega$. However, it has to be noted that such systems 
rely on wired connections to the sensor unit, involve complex circuits based on analog switches or operational amplifiers and have no restrictions on power consumption.

The prototyped system has been successfully applied to the contactless monitoring of the temperature and humidity inside a hermetic food box, adopting a resistive temperature sensor and a capacitive humidity sensor. The results show the ability to track the variations of the two quantities in the ranges $20-40{ }^{\circ} \mathrm{C}$ and $20-100 \% \mathrm{RH}$, respectively.

Author Contributions: M.D. contributed in the design and development of the system, experimental activity, analysis of experimental data, and in writing the paper. M.B. worked on the design and development of the system, contributed in the experimental activity, analysis of experimental data, and in writing and revising the paper. S.D. contributed in the development of the system and in revising the paper. M.F. contributed in revising the paper. V.F. coordinated the research and contributed in revising the paper.

Funding: This research received no external funding.

Conflicts of Interest: The authors declare no conflict of interest.

\section{References}

1. Čolaković, A.; Hadžialić, M. Internet of Things (IoT): A review of enabling technologies, challenges, and open research issues. Comput. Netw. 2018, 144, 17-39. [CrossRef]

2. Bedi, G.; Venayagamoorthy, G.K.; Singh, R.; Brooks, R.R.; Wang, K. Review of Internet of Things (IoT) in Electric Power and Energy Systems. IEEE Iot J. 2018, 5, 847-870. [CrossRef]

3. Liu, H.; Zhong, J.; Lee, C.; Lee, S.; Lin, L. A comprehensive review on piezoelectric energy harvesting technology: Materials, mechanisms, and applications. Appl. Phys. Rev. 2018, 5, 041306. [CrossRef]

4. Alghisi, D.; Ferrari, V.; Ferrari, M.; Touati, F.; Crescini, D.; Mnaouer, A.B. A new nano-power trigger circuit for battery-less power management electronics in energy harvesting systems. Sens. Actuators A 2017, 263, 305-316. [CrossRef]

5. Alghisi, D.; Ferrari, V.; Ferrari, M.; Crescini, D.; Touati, F.; Mnaouer, A.B. Single- and multi-source battery-less power management circuits for piezoelectric energy harvesting systems. Sens. Actuators A 2017, 264, 234-246. [CrossRef]

6. Wei, C.; Jing, X. A comprehensive review on vibration energy harvesting: Modelling and realization. Renew. Sustain. Energy Rev. 2017, 74, 1-18. [CrossRef]

7. Andò, B.; Baglio, S.; Bulsara, A.R.; Marletta, V.; Ferrari, V.; Ferrari, M. A low-cost snap-through-buckling inkjet-printed device for vibrational energy harvesting. IEEE Sens. J. 2015, 15, 3209-3220. [CrossRef]

8. Baù, M.; Ferrari, M.; Tonoli, E.; Ferrari, V. Sensors and energy harvesters based on piezoelectric thick films. Procedia Eng. 2011, 25, 737-744. [CrossRef]

9. Ferrari, M.; Alghisi, D.; Baù, M.; Ferrari, V. Nonlinear multi-frequency converter array for vibration energy harvesting in autonomous sensors. Procedia Eng. 2012, 47, 410-413. [CrossRef]

10. Ferrari, M.; Baù, M.; Cerini, F.; Ferrari, V. Impact-enhanced multi-beam piezoelectric converter for energy harvesting in autonomous sensors. Procedia Eng. 2012, 47, 418-421. [CrossRef]

11. Demori, M.; Ferrari, M.; Bonzanini, A.; Poesio, P.; Ferrari, V. Autonomous Sensors Powered by Energy Harvesting by von Karman Vortices in Airflow. Sensors 2017, 17, 2100. [CrossRef] [PubMed]

12. Alghisi, D.; Dalola, S.; Ferrari, M.; Ferrari, V. Triaxial ball-impact piezoelectric converter for autonomous sensors exploiting energy harvesting from vibrations and human motion. Sens. Actuators A 2015, 233, 569-581. [CrossRef]

13. Andò, B.; Baglio, S.; Baù, M.; Bulsara, A.R.; Ferrari, V.; Ferrari, M.; L'Episcopo, G. A nonlinear energy harvester by direct printing technology. Procedia Eng. 2012, 47, 933-936. [CrossRef]

14. Dalola, S.; Ferrari, M.; Ferrari, V.; Guizzetti, M.; Marioli, D.; Taroni, A. Characterization of thermoelectric modules for powering autonomous sensors. IEEE Trans. Instrum. Meas. 2009, 58, 99-107. [CrossRef]

15. Cuadras, A.; Gasulla, M.; Ferrari, V. Thermal energy harvesting through pyroelectricity. Sens. Actuator A 2010, 158, 132-139. [CrossRef]

16. Baù, M.; Ferrari, M.; Ferrari, V. Magnetless electromagnetic contactless interrogation technique for unwired conductive resonators. Electron. Lett. 2019, 55, 642-644. [CrossRef] 
17. Nopper, R.; Has, R.; Reindl, L. A wireless sensor readout system-Circuit concept, simulation, and accuracy. IEEE Trans. Instrum. Meas. 2011, 60, 2976-2983. [CrossRef]

18. Huang, Q.A.; Dong, L.; Wang, L.F. LC passive wireless sensors toward a wireless sensing platform: Status, prospects, and challenges. J. Microelectromech. Syst. 2016, 25, 822-840. [CrossRef]

19. Baù, M.; Ferrari, M.; Ferrari, V. Analysis and Validation of Contactless Time-Gated Interrogation Technique for Quartz Resonator Sensors. Sensors 2017, 17, 1264. [CrossRef]

20. Ferrari, M.; Baù, M.; Tonoli, E.; Ferrari, V. Piezoelectric resonant sensors with contactless interrogation for mass-sensitive and acoustic load detection. Sens. Actuators A 2013, 202, 100-105. [CrossRef]

21. Demori, M.; Baù, M.; Ferrari, M.; Ferrari, V. Electronic technique and circuit topology for accurate distance-independent contactless readout of passive LC sensors. Aeu Int. J. Electron. Commun. 2018, 92, 82-85. [CrossRef]

22. Demori, M.; Baù, M.; Ferrari, M.; Ferrari, V. Interrogation techniques and interface circuits for coil-coupled passive sensors. Micromachines 2018, 9, 449. [CrossRef] [PubMed]

23. Abdulhadi, A.E.; Denidni, T.A. Self-Powered Multi-Port UHF RFID Tag-Based-Sensor. IEEE J. Radio Freq. Identif. Rfid 2017, 1, 115-123. [CrossRef]

24. Caldara, M.; Nodari, B.; Re, V.; Bonandrini, B. Miniaturized Blood Pressure Telemetry System with RFID Interface. Procedia Eng. 2014, 87, 344-347. [CrossRef]

25. Volk, T.; Gorbey, S.; Bhattacharyya, M.; Gruenwald, W.; Lemmer, B.; Reindl, L.M.; Stieglitz, T.; Jansen, D. RFID Technology for Continuous Monitoring of Physiological Signals in Small Animals. IEEE Trans. Biomed. Eng. 2017, 62, 618-626. [CrossRef]

26. Sample, A.P.; Yeager, D.J.; Powledge, P.S.; Mamishev, A.V.; Smith, J.R. Design of an RFID-based battery-free programmable sensing platform. IEEE Trans. Instrum. Meas. 2008, 57, 2608-2615. [CrossRef]

27. Abada, E.; Zampolli, S.; Marco, S.; Scorzoni, A.; Mazzolai, B.; Juarros, A.; Gómez, D.; Elmi, I.; Cardinali, G.C.; Gómez, J.M.; et al. Flexible tag microlab development: Gas sensors integration in RFID flexible tags for food logistic. Sens. Actuators B 2007, 127, 2-7. [CrossRef]

28. Reverter, F.; Casas, O. Direct interface circuit for capacitive humidity sensors. Sens. Actuators A 2008, 143, 315-322. [CrossRef]

29. Czaja, Z. Time-domain measurement methods for $\mathrm{R}, \mathrm{L}$ and $\mathrm{C}$ sensors based on a versatile direct sensor-to-microcontroller interface circuit. Sens. Actuators A 2018, 274, 199-210. [CrossRef]

30. Reverter, F. Power Consumption in Direct Interface Circuits. IEEE Trans. Instrum. Meas. 2013, 62, 503-509. [CrossRef]

31. Siddiqui, A.; Mahboob, M.R.; Islam, T. A passive wireless tag with digital readout unit for wide range humidity measurement. IEEE Trans. Instrum. Meas. 2017, 66, 1013-1020. [CrossRef]

32. López-Lapeña, O.; Serrano-Finetti, E.; Casas, O. Low-power direct resistive sensor-to-microcontroller interfaces. IEEE Trans. Instrum. Meas. 2016, 65, 222-230. [CrossRef]

33. Nagarajan, P.R.; George, B.; Kumar, V.J. Improved single-element resistive sensor-to-microcontroller Interface. IEEE Trans. Instrum. Meas. 2017, 66, 2736-2744. [CrossRef]

34. Sreenath, V.; Semeerali, K.; George, B. A Resistive Sensor Readout Circuit with Intrinsic Insensitivity to Circuit Parameters and Its Evaluation. IEEE Trans. Instrum. Meas. 2017, 66, 1719-1727. [CrossRef]

35. Demori, M.; Baù, M.; Dalola, S.; Ferrari, M.; Ferrari, V. RFID powered system for contactless measurement of a resistive sensor array. In Proceedings of the IEEE International Instrumentation and Measurement Technology Conference (I2MTC), Houston, TX, USA, 11-14 May 2018. [CrossRef]

36. Güder, F.; Ainla, A.; Redston, J.; Mosadegh, B.; Glavan, A.; Martin, T.J.; Whitesides, G.M. Paper-Based Electrical Respiration Sensor. Angew. Chem. Int. Ed. 2016, 55, 5727-5732. [CrossRef] [PubMed]

37. Fantzke, A. A Low-Power Battery-Less Wireless Temperature and Humidity Sensor for the TI PaLFI Device. Texas Instruments Application Report. SWRA395. November 2011. Available online: http://www.ti.com/mcu/docs/litabsmultiplefilelist.tsp?sectionId=96\&tabId=1502\& literatureNumber $=$ swra395\&docCategoryId=1\&familyId=5013 (accessed on 28 April 2019).

(C) 2019 by the authors. Licensee MDPI, Basel, Switzerland. This article is an open access article distributed under the terms and conditions of the Creative Commons Attribution (CC BY) license (http://creativecommons.org/licenses/by/4.0/). 